\title{
Influence of Production Methodology on the Pozzolanic Activity of Sugarcane Bagasse Ash
}

\author{
Sujata Subedi ${ }^{1}$, Gabriel Arce, ${ }^{1, *}$, Marwa Hassan $^{1}$, Nitin Kumar $^{2}$, Michele Barbato $^{2}$, and Maria Teresa Gutierrez-Wing ${ }^{3}$ \\ ${ }^{1}$ Department of Construction Management, Louisiana State University, Baton Rouge, LA \\ ${ }^{2}$ Department of Civil and Environmental Engineering, University of California, Davis, CA \\ ${ }^{3}$ School of Renewable Natural Resources, Louisiana State University, Baton Rouge, LA
}

\begin{abstract}
Previous studies have shown the possibility of successful implementation of Sugarcane Bagasse Ash (SCBA) as a Supplementary Cementitious Material (SCM) in concrete production. However, its use has been constrained in the construction industry due to lack of a suitable largescale processing methodology of SCBA. In this study, the pozzolanic performance of SCBA produced using three different methodologies (i.e., uncontrolled burning, controlled burning, and post-processing of uncontrolled burning) was investigated. Experimental findings suggested that SCBA obtained from uncontrolled burning (raw SCBA) is not suitable for concrete application due to high carbon content. However, post-processing of raw SCBA yields a material with an adequate pozzolanic performance for concrete applications, which is comparable to SCBA produced under controlled burning conditions.
\end{abstract}

\section{Introduction}

Approximately, 0.7 to 0.9 ton of carbon dioxide $\left(\mathrm{CO}_{2}\right)$ is emitted into the atmosphere during the production of one ton of cement $[1,2]$. This alone contributes to about $5 \%$ of the global $\mathrm{CO}_{2}$ emissions and therefore constitutes a major environmental burden [3]. In addition, in recent years, the utilization of cement has increased significantly. For instance, in Louisiana, the consumption of cement increased from 1.8 million tons to 2.2 million tons in 2015 [4]. In turn, this amplifies the negative impact of cement production to the environment and increases the cost of the material. Thus, a sustainable alternative is needed to reduce the environmental burden and cost of concrete production.

Sugarcane bagasse fiber (SBF), is an agricultural byproduct from the extraction of sugarcane juice. In Louisiana, nearly 2.4 million tons of bagasse fiber are produced yearly [5]. Typically, bagasse fibers are burned by the sugar mills to mitigate the fire hazard presented by dry fibrous bagasse and to generate energy yielding raw Sugarcane Bagasse Ash (SCBA) [6]. Due to its high silica and aluminum oxide content, raw SCBA has the potential to be used as a partial replacement of cement in concrete [7]. However, since raw SCBA is produced from the uncontrolled burning of SBF (with hightemperature gradients), the material is heterogeneous with large particle size and high carbon content [8]. Hence, it cannot be used directly as a pozzolanic material in concrete.

The pozzolanic activity of SCBA is dependent on: (a) the silica, aluminum oxide, iron oxide, and carbon content after complete combustion of the SBF; (b) the amount of amorphous silica and crystalline silica phases formed during the burning process; and (c) the particle size of the SCBA [7, 9, 10]. Therefore, the pozzolanic activity of SCBA can be enhanced by an adequate processing methodology. Previous studies have shown that burning SBF under controlled condition yields a satisfactory pozzolanic material $[7,11]$. However, the yield of SCBA is low (about 4-5\%), which makes it unfeasible for large scale production [7]. For this reason, a processing methodology that can be utilized to produce SCBA with satisfactory pozzolanic properties from raw SCBA is of interest.

\section{Objectives}

This study aims to investigate the effect of different processing methodologies on the pozzolanic properties of SCBA in order to determine a processing procedure that is suitable for large scale implementation. The evaluated processing methodologies produce the following three materials: (1) raw SCBA (i.e., SCBA obtained directly from the mill and produced under uncontrolled burning conditions); (2) controlled SCBA (i.e., virgin $\mathrm{SBF}$ processed under controlled burning conditions); and (3) post-processed SCBA (i.e., raw SCBA from the mill post-processed to enhance its pozzolanic activity through controlled burning).

\section{Experimental program}

\subsection{Materials}

\footnotetext{
* Corresponding author: garcea $1 @$ lsu.edu
} 
Both SBF and raw SCBA used in this study were collected from Alma Plantation in Lakeland, Louisiana (USA). SBF and raw SCBA were used to produce the three different types of SCBA described above, i.e., raw SCBA, controlled SCBA, and post-processed SCBA. The production processes for each of the three materials are described below in detail.

\subsubsection{Raw SCBA}

Raw SCBA was obtained directly from the sugar mill, where SBF is burned under uncontrolled burning conditions. Raw SCBA was minimally processed by drying it at $65^{\circ} \mathrm{C}$ for 24 hours and sieving it using a No. $20(841 \mu \mathrm{m})$ sieve. The material thus obtained is designated here as SCBA-U.

\subsubsection{Controlled SCBA}

Controlled SCBA was obtained by processing SBF under controlled laboratory conditions. Initially, the SBF material was washed to remove impurities and subsequently air dried. Dry SBF was then pre-burned at $350^{\circ} \mathrm{C}$ in a muffle furnace for 1 hour. After completion of the pre-burning phase, the pre-burned SCBA was divided into equal parts using a splitter, to produce homogeneous samples. Subsequently, each part was burned for an additional 2 hours at $350^{\circ} \mathrm{C}$ and then burned at different specified temperatures ranging from $450^{\circ} \mathrm{C}$ to $650^{\circ} \mathrm{C}$ (at increments of $50^{\circ} \mathrm{C}$ ) for another three hours as shown in the experimental matrix on Table 1. All burned samples were allowed to cool inside the oven until the temperature reached $80^{\circ} \mathrm{C}$. The controlled SCBA specimens are designated as $\mathrm{C}-\mathrm{T}$, where $\mathrm{T}$ is the maximum calcination temperature.

\subsubsection{Post-processed SCBA}

Post-processed SCBA was obtained by post-processing raw SCBA in laboratory conditions. Initially, raw SCBA was dried at $65^{\circ} \mathrm{C}$ for 24 hours. Subsequently, the dry SCBA was sieved using a No. $20(841 \mu \mathrm{m})$ sieve to remove coarse particles. The sieved material was then separated into equal parts and burned under controlled conditions in a similar manner as the SBF used to produce controlled SCBA (two hours of pre-burning at $350^{\circ} \mathrm{C}$ followed by three hours of burning at the target temperature). The set of temperatures for post-process burning were the same as those used for the controlled SCBA production as shown in Table 1. All burned samples were allowed to cool inside the oven until a temperature of $80^{\circ} \mathrm{C}$ was reached. The post-processed ash was designated as $\mathrm{P}-\mathrm{T}$, where $\mathrm{T}$ is the maximum calcination temperature.

\subsection{Microstructure and chemical composition}

The properties of concrete containing SCMs are significantly affected by the chemical composition, size, and shape of pozzolanic materials utilized. Therefore, the chemical composition and morphology of the different SCBA materials produced were studied using Scanning Electron Microscopy (SEM) and Energy Dispersive X-Ray Spectroscopy (EDS). The scanning electron microscope used in this study was the Quanta ${ }^{\mathrm{TM}}$ 3D DualBeam ${ }^{\mathrm{TM}}$ FEG FIB-SEM, with EDAX Pegasus EDS/EBSD detectors.

Table 1. Experimental matrix.

\begin{tabular}{|c|c|c|c|}
\hline $\begin{array}{l}\text { Production } \\
\text { Methodology }\end{array}$ & $\begin{array}{l}\text { Calcination } \\
\text { Temp. }\left({ }^{\circ} \mathrm{C}\right)\end{array}$ & ID & Test (No. of Replicas) \\
\hline \multirow{5}{*}{$\begin{array}{l}\text { Controlled } \\
\text { SCBA }\end{array}$} & 450 & C-450 & \multirow{5}{*}{$\begin{array}{c}\text { Strength Activity } \\
\text { Index (6), } \\
\text { SEM/EDS (1), } \\
\text { LOI (1), } \\
\text { Moisture Content (1) }\end{array}$} \\
\hline & 500 & $\mathrm{C}-500$ & \\
\hline & 550 & C-550 & \\
\hline & 600 & C-600 & \\
\hline & 650 & C-650 & \\
\hline \multirow{5}{*}{$\begin{array}{l}\text { Post- } \\
\text { processed } \\
\text { SCBA }\end{array}$} & 450 & $\mathrm{P}-450$ & \multirow{5}{*}{$\begin{array}{c}\text { Strength Activity } \\
\text { Index (6), } \\
\text { SEM/EDS(1), LOI (1), } \\
\text { Moisture Content (1) }\end{array}$} \\
\hline & 500 & $\mathrm{P}-500$ & \\
\hline & 550 & $\mathrm{P}-550$ & \\
\hline & 600 & P-600 & \\
\hline & 650 & P-650 & \\
\hline \multicolumn{2}{|c|}{ Raw SCBA (Uncontrolled) } & SCBA-U & $\begin{array}{c}\text { Strength Activity } \\
\text { Index (6), } \\
\text { SEM/EDS(1), LOI (1), } \\
\text { Moisture Content (1) }\end{array}$ \\
\hline
\end{tabular}

\subsection{Moisture content and loss on ignition (LOI)}

The moisture content and loss on ignition (LOI) of pozzolans are important parameters since these can significantly affect the reactivity of such materials. In this study, the moisture content and LOI of the different SCBA materials were determined according to ASTM C311[12].

\subsection{Strength activity index (SAl)}

In this study, the pozzolanic activity of the different SCBA materials was determined by utilizing the Strength Activity Index (SAI) method according to ASTM C311 [12]. Before performing this test, all SCBA materials were grinded for 35 minutes using a jar mill at $300 \mathrm{rpm}$. Six control mortar cubes (2-inch side) were casted by mixing $500 \mathrm{~g}$ of ordinary Portland cement, $1375 \mathrm{~g}$ of standard graded sand, and $242 \mathrm{ml}$ of water. The flow value of the cement mortar was determined from the flow table test as per ASTM 1437 [13]. Subsequently, six cubes in which $20 \%$ of cement (by weight) was replaced by SCBA were prepared for each SCBA material evaluated in this study. The amount of water utilized for the cubes with SCBA was the water content necessary to produce the same flow value as that of the control mixture (within $\pm 5 \%$ tolerance). The compressive strength of the cubes was measured after 28 days of curing, and the strength activity index was calculated according to the following equation:

$$
\mathrm{SAI}=\left(\frac{X}{Y}\right) * 100
$$

where, $\mathrm{X}=$ average compressive strength of SCBA mixture cubes; and 
$\mathrm{Y}=$ average compressive strength of control mixture cubes.

It is important to notice that, per ASTM C618 [14], a minimum SAI of $75 \%$ is required for a material to qualify as an SCM.

\section{Results and discussion}

\subsection{Chemical composition and microstructure}

An EDS microchemical analysis was conducted to gain insight on the chemical composition of the different SCBAs considered in this study. EDS spectra were collected utilizing area mode, an accelerating voltage of $20 \mathrm{kV}$, and a current of $4 \mathrm{pA}$. The oxide compositions of the different SCBA materials obtained from the EDS analysis are presented in Table 2. All the controlled and post-processed SCBAs were mainly composed of $\mathrm{SiO}_{2}$, whereas raw SCBA was mostly composed of carbon. It is important to mention that $\mathrm{CO}_{2}$ content was not included in the oxide analysis of controlled and postprocessed SCBAs due to a high uncertainty in the $\mathrm{CO}_{2}$ estimation (due to very low carbon content).

Per ASTM C618, the total pozzolanic content (i.e., the sum of $\mathrm{SiO}_{2}, \mathrm{Al}_{2} \mathrm{O}_{3}$, and $\mathrm{Fe}_{2} \mathrm{O}_{3}$ ) must be a minimum of $50 \%$ for class $\mathrm{C}$ pozzolans and a minimum of $70 \%$ for class $\mathrm{N}$ and $\mathrm{F}$ pozzolans. From the results presented in Table 2, it is observed that, with the exception of raw SCBA (which did not qualify as a pozzolanic material and for which the pozzolanic content is reported in red), all SCBAs exhibited a pozzolanic content greater than $70 \%$. From these materials, C-650 and P-450 possessed the highest amount of pozzolanic contents among controlled and post-processed SCBAs, respectively.

The EDS analysis results indicated also that the amount of sulfur trioxide $\left(\mathrm{SO}_{3}\right)$ present in the different SCBAs was low. According to ASTM C618, the maximum allowable content of $\mathrm{SO}_{3}$ is $4 \%$ for class $\mathrm{N}$ pozzolans and $5 \%$ for class $\mathrm{F}$ and class $\mathrm{C}$ pozzolans. The results presented in Table 2 show that all the SCBAs evaluated in this study met this requirement.

In addition to the EDS analysis, SEM images were taken to observe the microstructure of the SCBAs. Figure 1 provides morphological information of the phases observed in the SCBA materials. From Figure 1a, it is observed that raw SCBA consisted of very large particles with highly irregular shapes including fiber-like particles. On the other hand, controlled SCBA particles (Figure 1b) were fine and varied shapes. In the case of post-processed SCBA (Figure 1c), large particles with irregular shape were observed; however, particles were smaller than those seen in raw SCBA.

Table 3 present the experimental results of moisture content and LOI tests according to ASTM C311. As shown in Table 3, the moisture content of all the SCBAs evaluated were well below the maximum moisture content limit of 3\% per ASTM C618. In the case of LOI, the maximum limits per ASTM C618 are 10\% for class $\mathrm{N}$ pozzolans and $6 \%$ for class $\mathrm{F}$ and class $\mathrm{C}$ pozzolans. As shown in Table 3 raw SCBA failed to meet ASTM C618 requirements by exhibiting a LOI of $12.28 \%$. However, all controlled and post-processed SCBAs exhibited low LOI values meeting ASTM C618 requirements for class $\mathrm{F}$ and class $\mathrm{C}$ pozzolans.

Table 2. SCBA oxide compositions (\%).

\begin{tabular}{|c|c|c|c|c|c|c|c|c|c|c|c|}
\hline Oxide & SCBA-U & C-450 & C-500 & C-550 & C-600 & C-650 & P-450 & $\mathbf{P}-500$ & P-550 & $\mathbf{P}-600$ & P-650 \\
\hline $\mathrm{CO}_{2}$ & 66.15 & - & - & - & - & - & - & - & - & - & - \\
\hline $\mathrm{Na}_{2} \mathrm{O}$ & 0.30 & 2.97 & 3.23 & 2.70 & 2.63 & 2.43 & 0.67 & 0.73 & 0.73 & 1.50 & 1.33 \\
\hline MgO & 0.45 & 2.03 & 2.07 & 1.67 & 1.87 & 1.47 & 1.23 & 2.53 & 2.53 & 2.20 & 2.10 \\
\hline $\mathbf{A l}_{2} \mathbf{O}_{3}$ & 2.65 & 9.50 & 9.13 & 7.93 & 8.20 & 7.83 & 7.40 & 7.50 & 7.50 & 11.00 & 10.57 \\
\hline $\mathrm{SiO}_{2}$ & 22.95 & 66.10 & 65.87 & 70.10 & 68.63 & 74.03 & 73.53 & 69.67 & 69.67 & 64.17 & 62.90 \\
\hline $\mathbf{P}_{2} \mathrm{O}_{5}$ & 3.00 & 5.20 & 5.07 & 2.23 & 3.00 & 1.13 & 2.37 & 2.27 & 2.27 & 2.10 & 3.53 \\
\hline $\mathrm{SO}_{3}$ & 0.00 & 1.43 & 1.47 & 0.97 & 1.23 & 0.63 & 0.33 & 0.47 & 0.47 & 0.50 & 0.70 \\
\hline $\mathbf{K}_{2} \mathbf{O}$ & 1.50 & 4.37 & 4.27 & 4.27 & 3.97 & 3.77 & 4.70 & 4.63 & 4.63 & 5.13 & 5.70 \\
\hline $\mathrm{CaO}$ & 1.55 & 4.50 & 4.80 & 5.17 & 4.60 & 4.40 & 4.73 & 7.73 & 7.73 & 5.20 & 6.33 \\
\hline $\mathrm{Fe}_{2} \mathrm{O}_{3}$ & 1.60 & 3.90 & 4.10 & 5.00 & 3.77 & 4.27 & 5.03 & 4.50 & 4.50 & 8.23 & 6.87 \\
\hline Pozzolanic Component $\left(\mathrm{SiO}_{2}+\mathrm{Al}_{2} \mathrm{O}_{3}+\mathrm{Fe}_{2} \mathrm{O}_{3}\right)$ & 27.20 & 79.50 & 79.10 & 83.03 & 80.60 & 8613 & 35.97 & 167 & 8167 & 3.40 & 80.33 \\
\hline
\end{tabular}

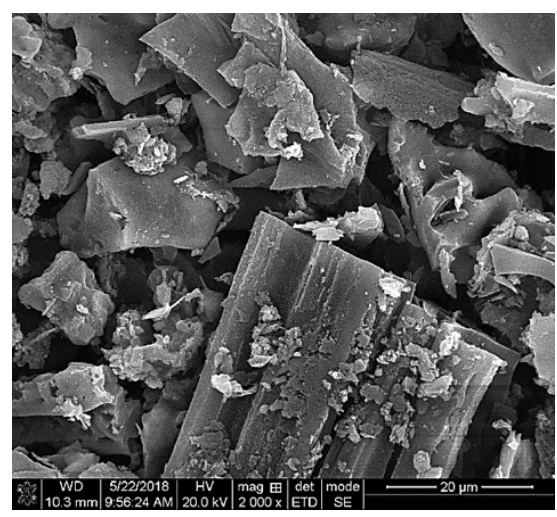

(a)

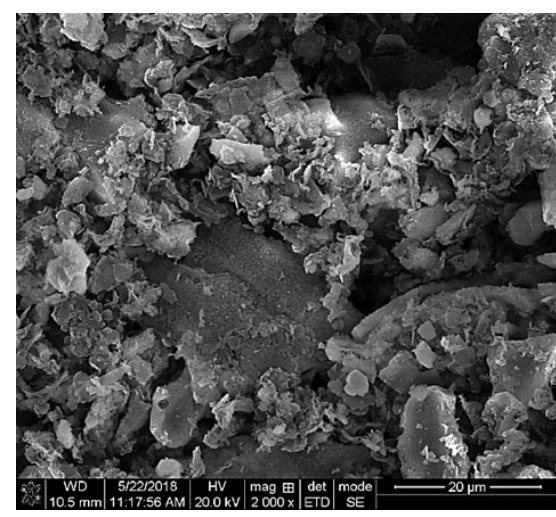

(b)

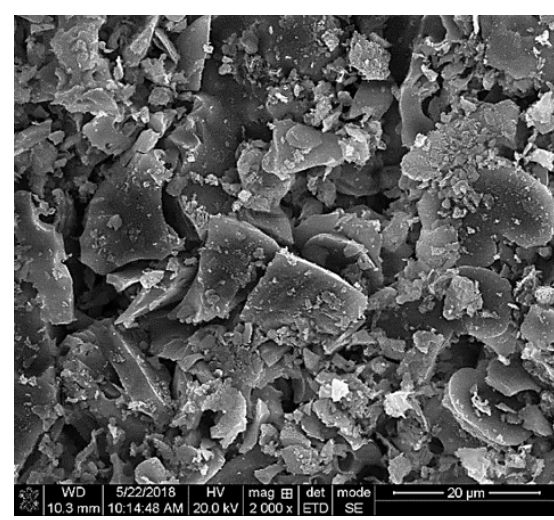

(c) 
Fig. 1. Microstructure of: (a) raw SCBA (b) controlled SCBA at $550^{\circ} \mathrm{C}(\mathrm{c})$ post-processed SCBA at $600^{\circ} \mathrm{C}$.

\subsection{Moisture content and LOI}

Table 3. Moisture content and LOI experimental results.

\begin{tabular}{|c|c|c|}
\hline ID & Moisture Content (\%) & LOI (\%) \\
\hline SCBA-U & 0.54 & 12.28 \\
\hline C-450 & 0.66 & 3.98 \\
\hline C-500 & 0.55 & 2.19 \\
\hline C-550 & 0.34 & 1.37 \\
\hline C-600 & 0.23 & 1.12 \\
\hline C-650 & 0.38 & 0.89 \\
\hline P-450 & 0.21 & 1.75 \\
\hline P-500 & 0.16 & 1.71 \\
\hline P-550 & 0.15 & 1.41 \\
\hline P-600 & 0.09 & 1.44 \\
\hline P-650 & 0.06 & 0.99 \\
\hline
\end{tabular}

\subsection{Strength activity index (SAI)}

The compressive strength results for cube specimens used to calculate the SAI values are shown in Figure 2. Based on the compressive strength results, SAI values were determined according to Eq. 1 and are presented in Table 4.

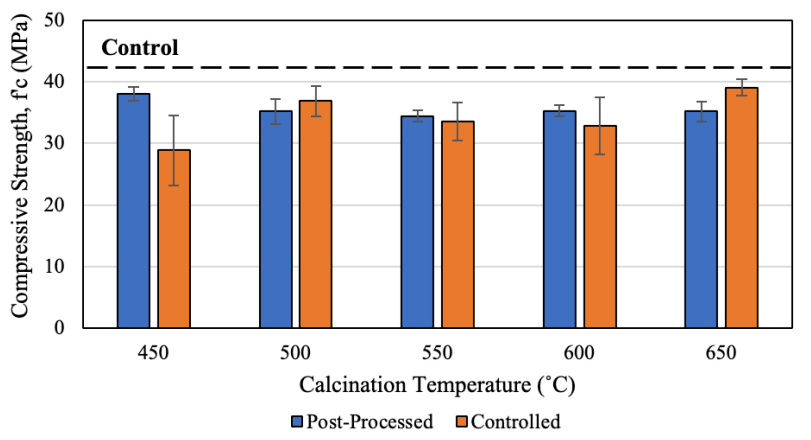

Fig. 2. Compressive strength results.

From Table 4, it is observed that the specimens containing raw SCBA exhibited a SAI of $68.72 \%$ (written in red), which is lower than the minimum requirement of $75 \%$ per ASTM C618 guidelines. The low SAI of raw SCBA mortar cubes was attributed to the high carbon content and the low pozzolanic component present in the raw SCBA, as shown in Table 2.

In the case of mortar cubes containing post-processed SCBAs, the SAI was above the $75 \%$ minimum requirement for all cases. This result is a clear indication of the positive influence that further processing of raw SCBA has on its pozzolanic properties. The maximum SAI obtained for post-processed SCBA was $89.64 \%$ and was obtained at the lowest calcination temperature of $450^{\circ} \mathrm{C}$. From the EDS results in Table 2, it is observed that the pozzolanic component of P-450 was the highest of the post-processed materials. Hence, the SAI results were supported by the EDS analysis.

For mortar cubes containing controlled SCBAs, the minimum ASTM requirement of $75 \%$ SAI was met for all controlled SCBA materials with the exception of C450 (likely due to the high LOI of this material). The maximum SAI obtained from mortar cubes containing controlled SCBAs occurred at a calcination temperature of $650{ }^{\circ} \mathrm{C}$ with a SAI of $92.13 \%$. The result was supported by the EDS oxide analysis since C-650 SCBA exhibited the highest pozzolanic component, as shown in Table 2.

Table 4. Strength activity index (SAI) results.

\begin{tabular}{|c|c|}
\hline ID & SAI (\%) \\
\hline SCBA-U & 68.72 \\
\hline C-450 & 68.02 \\
\hline C-500 & 86.88 \\
\hline C-550 & 79.07 \\
\hline C-600 & 77.41 \\
\hline C-650 & 92.13 \\
\hline P-450 & 89.64 \\
\hline P-500 & 82.91 \\
\hline P-550 & 81.21 \\
\hline P-600 & 83.19 \\
\hline P-650 & 82.97 \\
\hline
\end{tabular}

\section{Conclusions}

Based on the experimental findings of this study, the following conclusions are drawn:

- The processing methodology has a significant influence on the pozzolanic properties of the final SCBA product.

- Raw SCBA exhibited unsatisfactory pozzolanic properties by failing to meet the minimum requirements for pozzolanic component, SAI, and LOI per ASTM C618. Poor pozzolanic properties of raw SCBA can be attributed mainly to high carbon content.

- Pozzolanic properties of controlled SCBAs evaluated in this study met the requirements of ASTM C618 with the exception of C-450 which exhibited a low SAI (likely due to its high LOI). The highest pozzolanic component of $86.13 \%$ and the highest SAI of $92.13 \%$ were obtained at a calcination temperature of $650^{\circ} \mathrm{C}$ for controlled SCBA materials.

- $\quad$ Post-processing of raw SCBA proved to be highly beneficial to improve the pozzolanic properties of raw SCBA. Pozzolanic properties of postprocessed SCBAs evaluated in this study met the requirements of ASTM C618. The highest pozzolanic component of $85.97 \%$ and the highest SAI of $89.64 \%$ were obtained at a calcination temperature of $450^{\circ} \mathrm{C}$ for post-processed SCBA materials.

- Sulfur trioxide $\left(\mathrm{SO}_{3}\right)$ and moisture content requirements per ASTM C618 were met by all the materials evaluated in this study.

\section{References}

1. Li, C., Gong, X.Z., Cui, S.P., Wang, Z.H., Zheng, Y., and Chi, B.C. (2011). $\mathrm{CO}_{2}$ Emissions Due to Cement

\footnotetext{
* Corresponding author: garcea1@1su.edu
} 
Manufacture. Materials Science Forum 685: 181187.

2. Gregg, J.S., Andres, R.J., and Marland, G. (2008). China: Emissions Pattern of the World Leader in CO2emissions from Fossil Fuel Consumption and Cement Production. Geophysical Research Letters. 35(8): 2-6.

3. Huntzinger, D.N., and Eatmon, T.D. (2009). A LifeCycle Assessment of Portland Cement Manufacturing: Comparing the Traditional Process with Alternative Technologies. Journal of Cleaner Production. 17(7): 668-675.

4. PCA. (2016). Louisiana Cement Industry 2015. Portland Cement Association, New York City, New York Accessed on 10/25/2018 http://www.cement.org/docs/default-source/gapdfs/cement-industry-by-state2015/louisiana.pdf?sfvrsn=2.

5. American Sugar Cane League. (2017). Louisiana Sugarcane Industry Production Data 1975 to 2016.

6. Cordeiro, G.C., Tavares, L.M., and Filho, R.D.T. (2016). Improved Pozzolanic Activity of Sugar Cane Bagasse Ash by Selective Grinding and Classification. Cement and Concrete Research. 89: 269-75.

7. Cordeiro, G.C., Filho, R.D.T., and Fairbairn, E.M.R. (2009). Effect of Calcination Temperature on the Pozzolanic Activity of Sugar Cane Bagasse Ash. Construction and Building Materials. 23(10): 33013303.

8. Ramezanianpour, Ali Akbar. (2014). Metakolin Cement Replacement Materials, 225-255. Springer, Berlin, Heidelberg

9. Sompech, S., Dasri, T., and Thaomola, S. (2016). Preparation and Characterization of Amorphous Silica and Calcium Oxide from Agricultural Wastes. Oriental Journal of Chemistry. 32(4): 1923-1928.

10.Le Blond, J.S., Horwell, C.J., Williamson, J., and Oppenheimer, C. (2010). Generation of Crystalline Silica from Sugarcane Burning. Journal of Environmental Monitoring. 12(7): 1459-70.

11. Norsuraya, S., Fazlena, H., and Norhasyimi, R. (2016). Sugarcane Bagasse as a Renewable Source of Silica to Synthesize Santa Barbara Amorphous-15 (SBA-15). Procedia Engineering. 148: 839-846.

12. ASTM. (2005). ASTM C311/C311M Standard Test Methods for Sampling and Testing Fly Ash or Natural Pozzolans for Use in Portland-Cement Concrete. ASTM International, West Conshohocken, $P A$.

13. ASTM. (2005). ASTM C1437-15 Standard Test Method for Flow of Hydraulic Cement Mortar. ASTM International, West Conshohocken, PA.

14.ASTM. (2010). ASTM C618-17a Standard Specification for Coal Fly Ash and Raw or Calcined Natural Pozzolan for Use in Concrete. ASTM International, West Conshohocken, PA. 